\title{
EXAM AND QUIZ QUESTIONS WITH MULTIMEDIA RESPONSES
}

\author{
William H. Hubbard, Robert D. Murphy \\ Purdue University
}

\begin{abstract}
The next logical step to developing multimedia course materials is the use of immediate response grading of quizzes and exams. True - false, multiple choice and till in the blank type questions are adapted for use in multimedia authoring to provide visual and aural gratification. Scoring of the results provides the class room instructor with direct feedback.
\end{abstract}

\section{Introduction}

Electronic books provide the reader with the ability to jump in anywhere and hotword around. At one time traditional text book authors assumed people would begin reading and studying material with the first chapter and end with the last. With multimedia, this is no longer the required sequence. In actuality, no one really reads a book that way either. A word or a concept often comes up that requires the dictionary, glossary or index. Hopping around from place to place has always been part of the normal reading process. With electronic books, the authoring process provided hotwords and formalized the way we really read. Authors of electronic books provide the emphasized word transfer links. These hotwords are found as part of normal text but are given special emphasis with a change of color or font. These words are used to speed the reading process. Both remedial and advanced thought transfers are provided. This permits the learning of the basic idea without the author being either too wordy or too deep. With the electronic book concept, learning begins on a topic of interest to the student. He or she can begin reading any topic within any chapter and click around with the mouse controller to obtain remedial or advanced material.

Once the course materials are in multimedia format, multimedia quiz and exam questions can give the student and faculty instant gratification of successful learning and recommendations of evaluation. Have you ever heard a student respond that they had no idea how they did on a quiz or exam they just finished taking? If you feel they should be able to leave the testing arena with definite answers and positive attitude plans, you are ready for multimedia testing. With multimedia testing, the accuracy of each answer is immediately revealed and scored. Multimedia feedback can be used to provide additional encouragement or regret with suggested additional learning activities. In addition, the student is given the option of answering the question again if desired.

\section{How to make Multimedia Questions and Answers}

Using the CBT version of Asymetrix Toolbook $\mathbb{C}^{\prime}$, multimedia questions may use the same true / false, multiple choice or fill in the blank type questions that have been in the test bank for years. Answers may be weighted to provide the partial credit that students love to derive from instructors. If one answer is equivalent to another, equal weight is provided for each answer. If some answers are preferred to others, the author has the option of different weighting. Best of all, immediate response is given to answering each question. A part of each response may include both visual and aural stimuli to encourage the student to continue to do well and achieve at a higher level.

\section{Constructing the Question}

Nothing different is required in constructing a multimedia question. The same tried and true questions you have found beneficial in the past are still valid. Toolbook permits all the usual true - false, multiple choice or fill in the blank type questions. The following illustration is taken from Multimedia Electronics* summary questions on inverting voltage feedback. Notice the MORE button of Figure 1 entices the student to review material before answering the quiz question or after an incorrect answer.

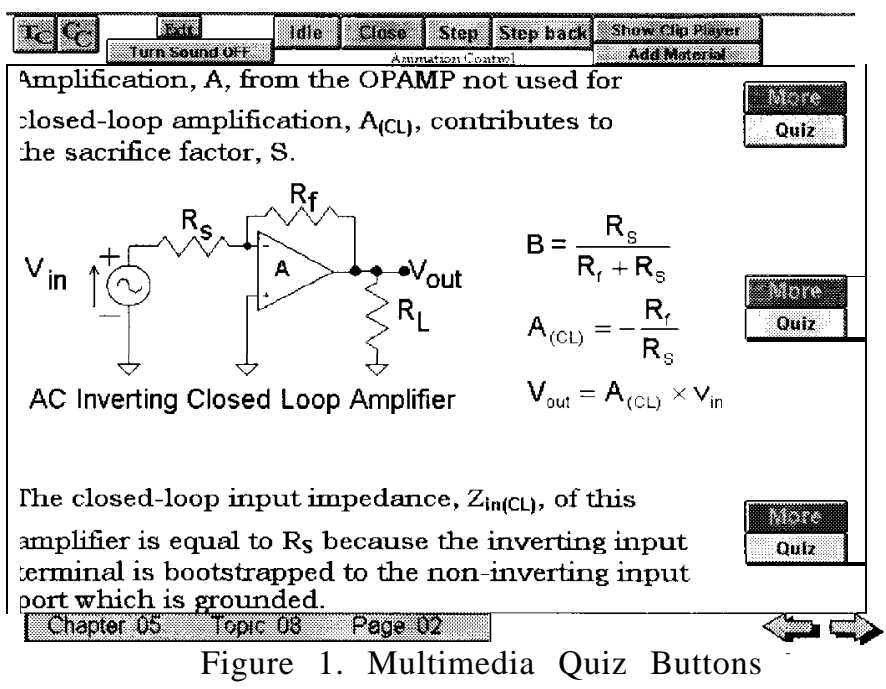

In this case selecting the first bright yellow quiz button in Figure 1, calls up the first multiple choice question in Figure 2. 


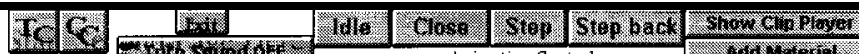

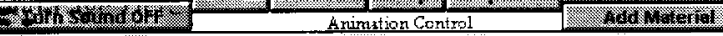

Determine the sacrifice factor for an inverting voltage feedback OPAMP amplifier whose open-loop amplification, $A$, is 300,000 and whose closed-loop amplification, $\mathrm{A}_{\mathrm{Cl}}$, is $\mathbf{- 3 0 0}$.
A. 001
1,000
A 600
100

Figure 2. Multimedia Quiz Question

\section{Answers are Entered and Weighted}

From the author mode of Toolbook, the question and selected answers are entered. The following answer dialog box of Figure 3 was used to generate the weighted answers to the previous question. Selecting the random answer option caused the different order of the answers in Figure 2 and Figure 5.

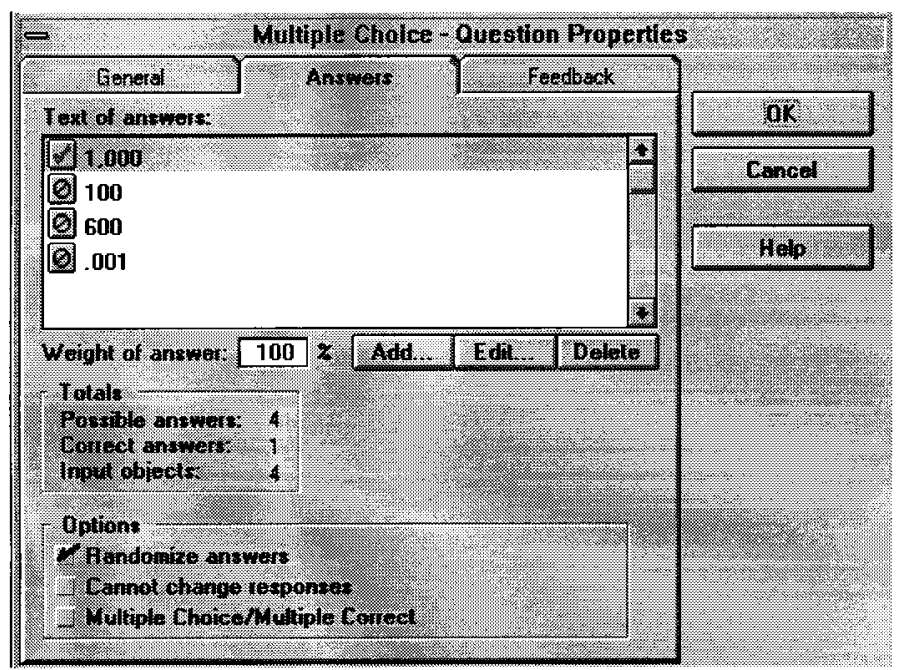

Figure 3. Question Answer Properties

Each answer can invoke a different author controlled response. From the feedback dialog box of Figure 4, the author may choose answer feedback in the form of text, media clips, event sequences or transfer to another page in the book. The text can range from one word, "Right!" or "Wrong!", to a lengthy explanation of the reasoning behind the answer. Examples of both types of response are found in Multimedia Circuits ${ }^{3}$ quiz questions. Animation video or sound clips may also be played as part of the student feedback.

Student generated feedback to the instructor is available on floppy disk or a network. This data includes the number of attempts to answer each question and the last answer.

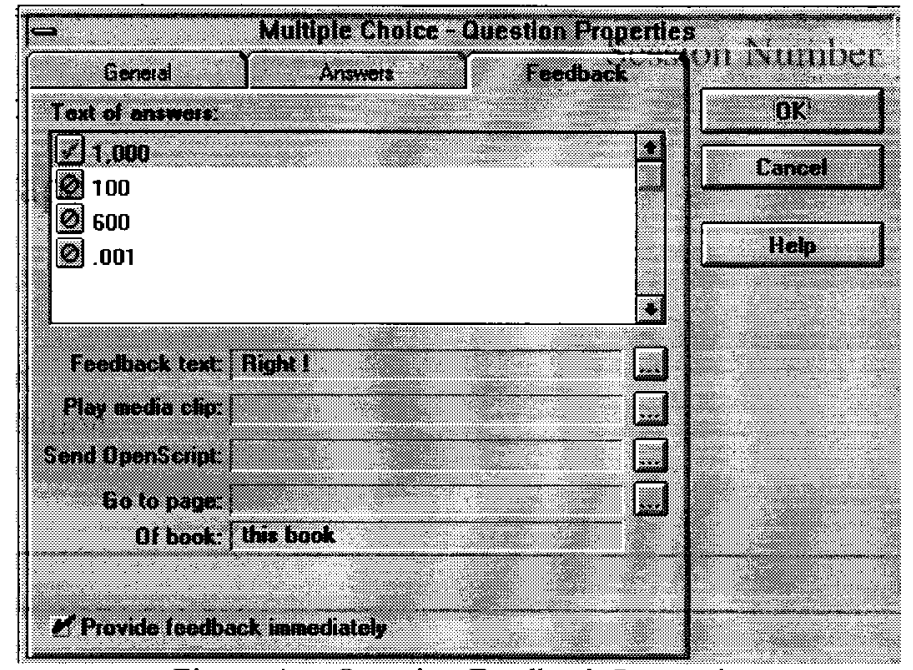

Figure 4. Question Feedback Properties

The Final Finished Question

Entering the reader mode of Toolbook to view the question as the student sees it in Figure 5, the selectable icon in front of the answer changes position and the programmed response is provided.

\begin{tabular}{|c|c|c|c|c|c|c|}
\hline $7 \%$ & 5.6. & Who & Closes & $\mathrm{staj}$ & Step frock & 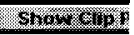 \\
\hline & Work Sound off & & Hnin & $x+10 n C$ & thol. & 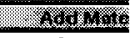 \\
\hline
\end{tabular}

Determine the sacrifice factor for an inverting voltage feedback OPAMP amplifier whose open-loop amplification, A, is 300,000 and whose closed-loop amplification, $A_{C L}$, is -300 .

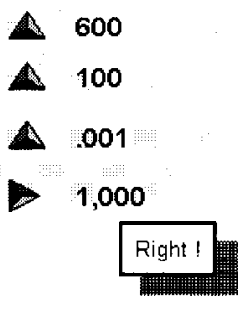

Figure 5. Multimedia Quiz Question with Response

Conclusion

Multimedia authoring includes the capability for testing the student and providing instant feedback in the form of visual or aural stimuli. The questions may be standard true / false, multiple choice or fill in the blank. The instructor can get the results of the student's efforts to measure their understanding of the material.

\section{References:}

1. Asymetrix Corporation, Toolbook CBT version, 110-11 O'h Avenue N. E., Suite 700, Bellevue, WA 98004

2. Hubbard, William H., and Robert D. Murphy, Multimedia Electronics, Prentice Hall.

3. Murphy, Robert D., Multimedia Circuits, Prentice Hall 